African 'flexibility' may open path to
biosafety agreement

[LONDON] A United Nations conference held to reach a global protocol on the safety of genetically modified organisms opened this week in Cartagena, Colombia, with signs that African countries are preparing to compromise in order to achieve a positive outcome.

Until now, the Africa group has demanded a comprehensive legal instrument to cover the transport and impact of all genetically modified produce. "We're ready for debate. But we also want to be flexible," says Tewolde Berhan Egziabher, general manager of the Environmental Protection Agency of Ethiopia, who acts as the group's spokesman.

Egziabher says the group may be willing to compromise on its insistence that exporters would need consent from an importing country before shipping all types of genetically modified material. "We realize that there is a difference between live and dead modified organisms," he says, adding that the need for advance informed agreement may not apply to all types of modified produce.

The protocol will be finalized at the end of the special conference of the UN biodiversity convention next Tuesday (23 February). African countries are aware that failure to agree on a protocol will benefit their main opponents in the negotiations, the so-called 'Miami group' of countries, which includes the United States, Canada and other large agriculture-exporting countries.

This group, along with biotechnology and agri-chemical companies, wants a protocol restricted to regulating trade in live genetically modified organisms. They believe that a protocol that extends to genetically modified products will impede international trade.

But Egziabher says the Africa group will not shift on other contentious issues including demands for a regime for compensation in the event of transport accidents, and recognition of a country's right to refuse shipment of any genetically modified material.

Countries in the European Union, in particular, argue that countries should only be allowed to refuse shipment if genetically modified material fails an agreed scientific risk assessment of its impact, for example on biodiversity. But Egziabher says that the criteria should include the socio-economic effect of importing the material, as well as public attitudes to genetic modification.

Val Giddings, a vice-president of the Biotechnology Industry Organization in the United States, believes that few countries will agree to a treaty along these lines. He believes that the Africa group's concerns about the impact of genetic modification on biodiversity are misplaced, and claims that biotechnology benefits biodiversity. Ehsan Masood

\title{
Scientists defend French ex-ministers in blood trial
}

[PARIS] The prosecution's case against three former ministers in France's 'contaminated blood' affair has been strongly challenged by a number of prominent AIDS scientists in a trial that opened in Paris last week.

Former prime minister Laurent Fabius, former minister of social affairs and national solidarity Georgina Dufoix, and her secretary of state, Edmond Hervé, are charged with involuntary homicide and involuntary harm to the physical integrity of persons. They are accused of negligence in their handling of the risk of the transmission of AIDS in the blood supply in 1985, and of having failed to take sufficient precautions to safeguard public health.

But Jean Bernard, a retired haematologist and former chairman of the French national ethics committee, told the court he did not believe that the ministers had been negligent, in particular given the uncertainties and pace of events in AIDS research at the time.

A key allegation is that the introduction of a US test manufactured by Abbott Laboratories was delayed to protect the national market for a French test, marketed by Diagnostics Pasteur. Fabius announced the decision to introduce systematic testing of blood donations for AIDS on 19 June 1985.

But Willy Rozenbaum, a pioneer of AIDS research, described a "remarkable indifference" in the scientific and medical communities in the early 1980s to the threat of AIDS. In a blow to the prosecution case, he said he had felt at the time that Fabius' decision to introduce screening was "precocious".

Rozenbaum said he was concerned that introducing screening for blood donations might actually increase the contamination of blood supplies. In the absence of a wider AIDS prevention strategy, including the creation of centres for free and anonymous testing of anyone who wanted it, he feared that introducing screening might prompt a rush to give blood from at-risk individuals as a means to get tested. And given concern that the available tests still gave false negatives, he feared that more contaminated blood would slip through the system.

Fabius denied any knowledge of the discussions of an interministerial meeting on 9 May 1985, chaired by François Gros, a former director of the Institut Pasteur, which decided that approval of the Abbott test should be held back "for some time". He claimed he had acted as quickly as possible and taken the decision to introduce systematic screening of blood while experts were still divided.

Gros has admitted that there was discussion about whether to protect the Pasteur test (see Nature 367, 673; 1994), but he denies that this played a role in any delay, arguing that it was just one element in a much wider picture, the major factor having been the costs of screening.

Fabius asserted that his decision to implement screening was not based on industrial considerations. He argued, in particular, that the prosecution had incorrectly interpreted a key document. This was a note by an adviser, dated 29 April 1985, which recommended the introduction of screening, but with timing favourable to Diagnostics Pasteur.

In the margin of this note, Fabius had scribbled "I'm in favour, I will perhaps announce a decision in ten days". "It is from this that I am presented as the chefd'orchestre of a conspiracy favourable to Pasteur," said Fabius, arguing that his comments referred only to the need to introduce screening.

His defence also produced a letter dated 28 August 1985 from Christian Policard, the president director-general of Diagnostics Pasteur, bemoaning the fact that France was unique in having adopted a "liberal attitude to foreign tests", and alleging that all other countries had introduced protectionist measures for their own tests.

Rozenbaum, who was booed as he testified, told the court that "economic problems are permanently linked to medicine".

Luc Montagnier, a researcher at the Insitut Pasteur and a member of the group that discovered the AIDS virus, said it was always possible to do things faster with hindsight, but that he felt at best only "a few weeks could have been saved" had the implementation of screening being handled differently.

A potentially lethal blow to the prosecution case came from Michel Setbon, a researcher at the Centre National de la Recherche Scientifique, who has studied screening policies in the United Kingdom, Sweden and France. Setbon told the court that "there is no relationship of cause and effect between the introduction of the diagnostic tests and the [level] of contamination".

He pointed out that the level of post-tranfusion contaminations was 13 times higher in France than in the United Kingdom, even though systematic screening of donated blood was implemented in August 1985, two months earlier than in the United Kingdom.

The principal cause of the higher level of contamination in France, he said, was the failure to implement a 1983 circular intended to exclude blood donations from highrisk groups such as drug addicts. In contrast, such measures were rigorously applied in the United Kingdom and Sweden.

The trial of the former ministers is scheduled to last three weeks.
Declan Butler 